\title{
Estimation of the Range of Variation in the Mineral Composition of Silicate Lake Bottom Sediments Using Data from XRD and XRF
}

\author{
Roman V. Smelyi*a, \\ Alexander L. Finkelshtein ${ }^{a}$, Igor S. Yakimov ${ }^{b}$, \\ Alena A. Amosova a and Victor M. Chubarov ${ }^{\mathrm{a}}$ \\ ${ }^{a}$ Vinogradov Institute of Geochemistry SB RAS \\ Irkutsk, Russian Federation \\ ${ }^{b}$ Siberian Federal University \\ Krasnoyarsk, Russian Federation
}

Abstract. A method is proposed for estimating the range of mineral group content in the cores of silicate bottom sediments of lakes based on the search for the minimum and maximum content of stoichiometric minals that make up the group of minerals, provided that the balance of the mineral composition and the content of elements in the sample is observed. The mineral components were determined using the method of qualitative X-ray phase analysis, the contents of the main rock-forming elements were determined by X-ray fluorescence analysis. Comparison with the results of quantitative $\mathrm{X}$-ray phase analysis showed that the contents of mineral groups either lie in the range calculated in the extreme search procedure based on data on the element composition, or overlap with the calculated range within the measurement error. The systematic discrepancy between the results of calculating the range of content of the silicon dioxide phase and the results of quantitative X-ray phase determination of quartz observed for the samples under consideration is due to the presence of an X-ray amorphous phase of biogenic silica. The proposed method for estimating the range of mineral group content is easy to implement, uses the publicly available MS Excel software, and can be useful for estimating variations in mineral composition by core depth, in conditions of frequent shortages of individual sample material distributed between different methods of analysis.

Keywords: X-ray phase analysis, X-ray fluorescence analysis, XRD, XRF, mineral composition, silicate lake bottom sediments.

(C) Siberian Federal University. All rights reserved

This work is licensed under a Creative Commons Attribution-NonCommercial 4.0 International License (CC BY-NC 4.0).

* Corresponding author E-mail address:srv47@yandex.ru 
Citation: Smelyi R.V., Finkelshtein A.L., Yakimov I.S., Amosova A.A., Chubarov V.M. Estimation of the range of variation in the mineral composition of silicate lake bottom sediments using data from XRD and XRF, J. Sib. Fed. Univ. Chem., 2020, 13(2), 260-272. DOI: 10.10.17516/1998-2836-0180

\title{
Оценка диапазона вариации минерального состава силикатных озерных донных отложений \\ с использованием данных методов \\ рентгеновской дифракции \\ и рентгенофлуоресцентного анализа
}

\author{
Р.В. Смелыйа \\ И.С. Якимов ${ }^{\tilde{\sigma}}$ А.А. Амосова ${ }^{\mathrm{a}}$, В.М. Чубаров ${ }^{\mathrm{a}}$ \\ ${ }^{a}$ Институт геохимии им. А.П. Виноградова СО РАН \\ Российская Федерачия, Иркутск \\ ${ }^{6}$ Сибирский федеральный университет \\ Российская Федерация, Красноярск
}

\begin{abstract}
Аннотация. Предложен способ оценки диапазона содержания минеральных групп в кернах силикатных донных отложений озер на основе поиска минимума и максимума содержаний стехиометрических миналов, составляющих группы минералов, при условии соблюдения баланса минерального состава и содержания элементов в пробе. Минеральные составляющие определены с помощью метода качественного рентгенофазового анализа, содержания основных породообразующих элементов определены методом рентгенофлуоресцентного анализа. Сравнение с результатами количественного рентгенофазового анализа показало, что содержания минеральных групп либо лежат в диапазоне, рассчитанном в процедуре поиска экстремума на основе данных об элементном составе, либо перекрываются с рассчитанным диапазоном в пределах погрешности измерения. Наблюдаемое для рассматриваемых составов проб систематическое расхождение результатов расчета диапазона содержания фазы диоксида кремния и результатов количественного рентгенофазового определения кварца обусловлено присутствием рентгеноаморфной фазы биогенного кремнезема. Предлагаемый способ оценки диапазона содержания минеральных групп прост в реализации, использует общедоступное программное обеспечение MSExcel и может быть полезен для оценки вариации минерального состава по глубине керна, в условиях часто имеющего место дефицита материала отдельных проб, распределяемого между различными методами анализа.
\end{abstract}

Ключевые слова: рентгенофазовый анализ, рентгенофлуоресцентный анализ, минеральный состав, силикатные озерные донные отложения. 
Цитирование: Смелый, Р.В. Оценка диапазона вариации минерального состава силикатных озерных донных отложений с использованием данных методов рентгеновской дифракции и рентгенофлуоресцентного анализа / Р.В. Смелый, А.Л. Финкельштейн, И.С. Якимов, А.А. Амосова, В.М. Чубаров // Журн. Сиб. федер. ун-та. Химия, 2020. 13(2). C. $260-272$. DOI: $10.17516 / 1998-2836-0180$

\section{Введение}

Донные отложения озер Восточной Сибири представляют интерес с точки зрения возможности изучения изменений природной среды и климата континентальных регионов в прошлом для верификации имеющихся климатических моделей [1-4]. Важным индикатором режима накопления озерных осадков является их минеральный и элементный состав, несущий в себе отклик на изменение климата водосборного бассейна. Для определения содержания основных породообразующих элементов в озерных осадках при палеоклиматических исследованиях получил распространение метод рентгенофлуоресцентного анализа [5-8], обеспечивающий относительное стандартное отклонение, характеризующее погрешность анализа в 1-5 \%. Для определения минерального состава используют метод рентгеновской порошковой дифрактометрии [1, 2, 9-11]. Индикаторами изменений климата водосборного бассейна могут служить глинистые минералы $[12,13,14]$, минералы группы карбонатов $[2,15]$, кварц и полевые шпаты [9], др. Применение количественного рентгенофазового анализа минерального состава осадочных горных пород сталкивается с рядом трудностей, среди которых можно отметить сложность идентификации отдельных минеральных фаз переменного нестехиометрического элементного состава, погрешности, обусловленные преимущественной ориентацией в порошке таких силикатов, как слюды и глинистые минералы [12], присутствие изоморфных примесей элементов в карбонатах [2], и др. Анализ погрешностей определения глинистых минералов по результатам межлабораторных испытаний приведен в работе [16]. Следует также отметить присутствие в озерных отложениях аморфных фаз, таких как биогенный кремнезем и органическое вещество. Упомянутые причины приводят к значительному различию в содержаниях элементов, определенных методами химического анализа и вычисленных из данных количественного рентгенофазового анализа. Авторы работ $[1,14]$ применили физико-химическое моделирование и симплекс-метод линейной оптимизации для оценки содержания глинистых минералов, полевых шпатов, кварца, мусковита в образцах кернов донных отложений на основе данных химического элементного анализа. В работе [11] приведены оценки неопределенности содержания некоторых минеральных групп в карбонатно-силикатных донных отложениях, полученные сравнением данных физикохимического моделирования минерального состава [14] и рентгеновской дифрактометрии, величина которых составила 10-30 \%. Такая величина неопределенности при уровне содержаний 10-40 \% массовой доли сопоставима с оценкой относительной погрешности $15-30 \%$, рассчитанной по формуле $\left( \pm 100 * X^{-0.5} \%\right.$, где $\mathrm{X}$ - мас. \%), используемой при межлабораторных испытаниях [16]. Очевидно, что элементный состав накладывает некоторые ограничения на возможный минеральный состав. В настоящей работе мы рассматриваем способ оценки диапазона содержания минеральных групп в силикатных отложениях озер на основе поиска экстремума (минимума или максимума) содержания стехиометрических миналов, составляющих группы минералов, при условии соблюдения баланса минерального состава и содержания элементов в пробе, определенных с помощью рентгенофлуоресцентного анализа.

$$
-262-
$$




\section{Экспериментальная часть}

\section{Объект исследования}

В качестве объекта исследования выбраны образцы донных отложений высокогорных озер Хикушка и Ильчир, расположенных в горах Восточного Саяна. Оз. Хикушка каровое, проточное, расположено на высоте 1956 м над уровнем моря. Площадь его поверхности составляет 0,3 км², глубина достигает 42 м. Керн длиной 123 см отобран с глубины 30 м, возраст отложений в керне определен методом радиоуглеродного анализа и составляет 14600 лет.

Оз. Ильчир, из которого вытекает р. Иркут, расположено на высоте 1952 м и имеет комплексное ледниково-тектоническое происхождение. Максимальная глубина озера составляет 42 м, керн длиной 133 см получен с глубины 39 м. Возраст отложений в керне 8400 лет.

Керны были разрезаны с шагом в 1 см. Затем образцы осадков каждого сантиметра керна были распределены для различных методов анализа (элементный и минеральный (фазовый) анализ, палинологический, анализ изотопов углерода, кислорода, органического вещества, определение биогенного кремнезема и некоторые др.). Приблизительно 150 мг образца было использовано для рентгенофлуоресцентного анализа, 1.5-2 г каждого третьего сантиметра керна - для рентгенофазового анализа.

\section{Аппаратура и условия измерения}

Определение основных породообразующих элементов проводили на рентгенофлуоресцентном спектрометре с волновой дисперсией S8 Tiger (Bruker AXS). Спектрометр оснащен рентгеновской трубкой с Rh-анодом мощностью 4 кВт. Образцы для измерения готовили сплавлением 110 мг высушенного и прокаленного при $950{ }^{\circ} \mathrm{C}$ материала с 1 г флюса (метабората лития) в электропечи в платиновых тиглях при температуре $1050{ }^{\circ} \mathrm{C}$. Экспозиции измерения аналитических линий обеспечивали стандартное отклонение измерения скорости счета менее 1 отн. \%. Общее время измерения одной пробы составляло приблизительно 10 мин. Детали методики измерения и подготовки проб приведены в работах $[7,8]$.

Определение минерального состава проводили на рентгеновском порошковом дифрактометре D8 ADVANCE (Brucker AXS). Дифрактометр оснащен рентгеновской трубкой с Cuанодом. Напряжение и ток рентгеновской трубки: 40 кВ, 40 мА. Измерения проводили в диапазоне дифракционных углов $2 \theta$ от 3 до $80^{\circ}$ с шагом сканирования $0.02^{\circ}$. Экспозиция измерения 1 с/шаг, вращение образца 15 об/мин. Общее время измерения одной дифрактограммы составляло приблизительно 60 мин. Образцы для измерения готовили набивкой и выравниваем порошка в кювете. Относительное стандартное отклонение (RSD) подготовки пробы и измерения интенсивности главных пиков кварца и полевого шпата, оцененное по результатам измерения шести приготовленных образцов смеси кварца и микроклина, составило $5.2 \%$ при содержаниях в диапазоне $25-75$ мас. \%.

Количественный фазовый анализ по методу Ритвельда выполняли с помощью программы TOPAS 4 пакета DIFFRACplus дифрактометра D8 ADVANCE [17, 18] с базой данных порошковой дифрактометрии PDF-2 [19] и по варианту метода ссылочных интенсивностей (RIR) с помощью программного пакета [20], разработанного в лаборатории рентгеновских методов анализа Сибирского федерального университета. Отношения интенсивности пика фазы и главного пика корунда выбраны из базы данных PDF-2.

$$
-263-
$$




\section{Результаты и обсуждение}

В табл. 1 приведены вариации содержания основных породообразующих элементов в пересчете на оксиды в исходных сухих пробах, определенные рентгенофлуоресцентным методом, и вариации потерь при прокаливании (ППП) для осадков оз. Ильчир. В пробах также присутствует фосфор и марганец в содержании менее 0.5 мас. \%. Диапазоны вариации содержания оксидов элементов в пробах оз. Хикушка лежат в пределах диапазонов, приведенных в табл. 1. Пробы оз. Хикушка отличаются меньшей величиной ППП в диапазоне 8-15 мас. \%. Для ограниченной изза дефицита материала выборки проб были определены потери при прокаливании при $600{ }^{\circ} \mathrm{C}$, которые обусловлены преимущественно органической составляющей. Приблизительно 90 \% массы ППП при $950{ }^{\circ} \mathrm{C}$ составляет органическое вещество. Как будет показано далее, карбонатные минералы в пробах не обнаружены и, следовательно, приблизительно 10 \% ППП обусловлены главным образом потерями связанной воды в глинистых минералах и слюдах.

Дифрактограмма одного из исследуемых образцов донных отложений оз. Ильчир представлена на рис. 1. В образцах идентифицированы минеральные фазы, список которых приведен в табл. 2. Минерал рутил определяется с низкой степенью достоверности, но был включен в обработку дифрактограмм, поскольку оксид титана присутствует в сравнительно высоких содержаниях, достигающих 1 мас. \%. Корреляционный анализ данных элементного состава в некоторых общих чертах согласуется с минеральным составом, отраженным в табл. 2. Высокие положительные величины коэффициента корреляции $R>0.7$ наблюдаются между содержания-

Таблица 1. Диапазоны содержания основных породообразующих компонентов в пробах оз. Ильчир

Table 1. Ranges of the main rock-forming components content in samples of Lake Ilchir

\begin{tabular}{|c|c|c|c|c|c|}
\hline Компонент & $\begin{array}{c}\text { Диапазон } \\
\text { содержания, мас. \% }\end{array}$ & Компонент & $\begin{array}{c}\text { Диапазон } \\
\text { содержания, мас. \% }\end{array}$ & Компонент & $\begin{array}{c}\text { Диапазон } \\
\text { содержания, мас. \% }\end{array}$ \\
\hline $\mathrm{Na}_{2} \mathrm{O}$ & $1.3-2.7$ & $\mathrm{SiO}_{2}$ & $43-54$ & $\mathrm{TiO}_{2}$ & $0.6-0.9$ \\
\hline $\mathrm{MgO}$ & $3.1-4.7$ & $\mathrm{~K}_{2} \mathrm{O}$ & $1.7-2.3$ & $\mathrm{Fe}_{2} \mathrm{O}_{3 \text { tot }}$ & $6.6-10$ \\
\hline $\mathrm{Al}_{2} \mathrm{O}_{3}$ & $13-17$ & $\mathrm{CaO}$ & $2-3$ & ППП & $10-24$ \\
\hline
\end{tabular}

Таблица 2. Минеральные фазы, идентифицированные в образцах осадков

Table 2. Mineral phases identified in precipitation samples

\begin{tabular}{|c|c|c|}
\hline Имя минерала в базе PDF-2 & Код в базе PDF-2 & Химическая формула \\
\hline Кварц (Quartz ) & $79-1910$ & $\mathrm{SiO}_{2}$ \\
\hline Ортоклаз (Orthoclase) & $71-1540$ & $\mathrm{KAlSi}_{3} \mathrm{O}_{8}$ \\
\hline Альбит (Albite) & $9-466$ & $\mathrm{NaAlSi}_{3} \mathrm{O}_{8}$ \\
\hline Анортит (Anorthite) & $41-1486$ & $\mathrm{CaAl}_{2} \mathrm{Si}_{2} \mathrm{O}_{8}$ \\
\hline Клинохлор (Clinochlore) & $16-362,16-363$ & $\left(\mathrm{Mg}, F e_{5} \mathrm{Al}_{\left(\mathrm{AlSi}_{3} \mathrm{O}_{10}\right)(\mathrm{OH})_{8}}\right.$ \\
\hline Мусковит (Muscovite) & $7-25$ & $\mathrm{KAl}_{3} \mathrm{Si}_{3} \mathrm{O}_{10}(\mathrm{OH})_{2}$ \\
\hline Амфибол (Actinolite) & $4-594$ & $\mathrm{Ca}_{2}\left(\mathrm{Mg}_{5} \mathrm{Fe}^{++}\right)_{5} \mathrm{Si}_{8} \mathrm{O}_{22}(\mathrm{OH})_{2}$ \\
\hline Рутил (Rutile) & $76-324$ & $\mathrm{TiO}_{2}$ \\
\hline
\end{tabular}




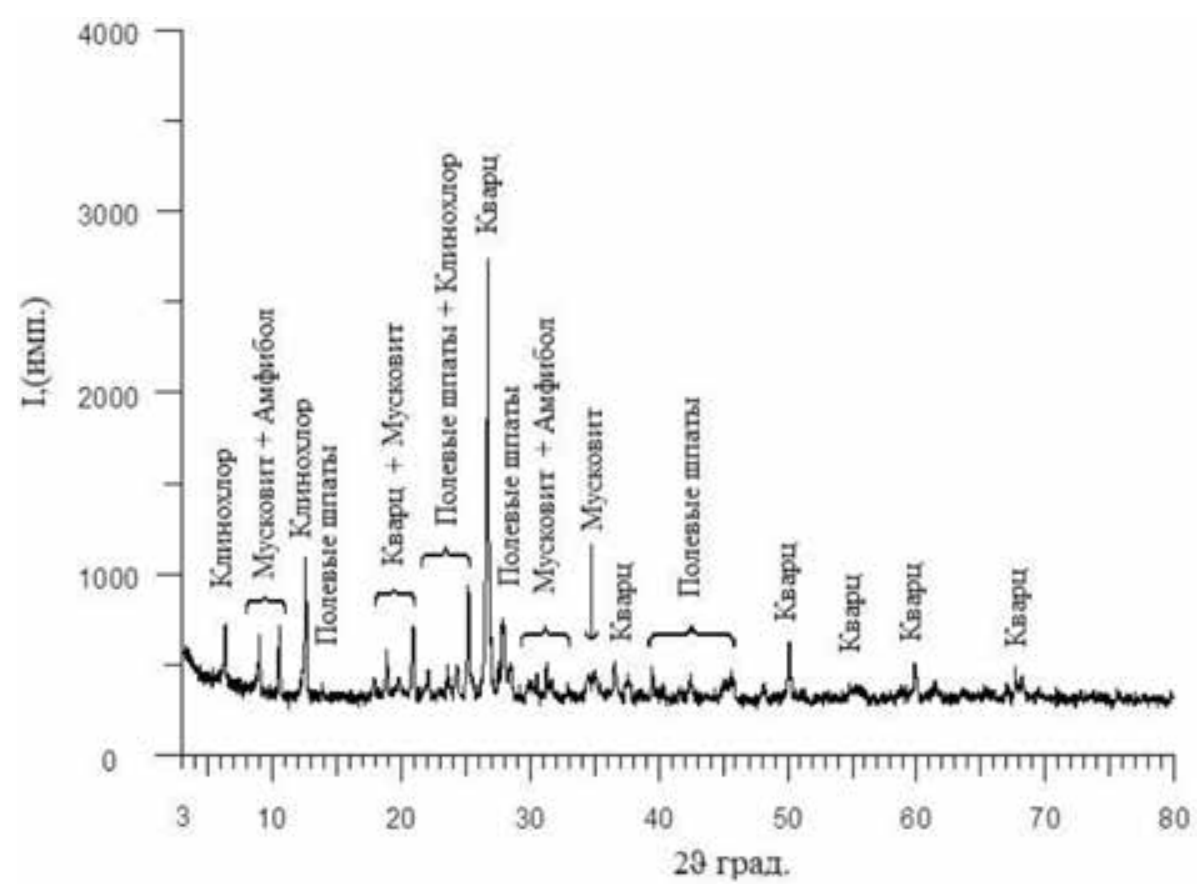

Рис. 1. Дифрактограмма образца донных отложений оз. Ильчир

Fig. 1. X-ray powder diffraction pattern of one of the samples of bottom sediments of Lake Ilchir

ми $\mathrm{SiO}_{2}$ и содержаниями $\mathrm{Na}_{2} \mathrm{O}$ и $\mathrm{CaO}$; между содержаниями $\mathrm{Al}_{2} \mathrm{O}_{3}$ и $\mathrm{K}_{2} \mathrm{O}$, и это свидетельствует о наличии группы полевых шпатов. Невысокие величины $R<0.6$ между содержанием $\mathrm{Fe}_{2} \mathrm{O}_{3}$ и $\mathrm{MgO}$ свидетельствуют о том, что эти элементы распределены среди различных групп минералов. Карбонатные минералы не обнаружены, и это согласуется с данными об элементном составе и данными о ППП при $600{ }^{\circ} \mathrm{C}$. В образцах оз. Хикушка вероятно присутствие вермикулита в небольшом содержании - 1-2 мас. \%. Этот минерал не был включен в дальнейшее рассмотрение из-за низкого содержания и относительно низкой достоверности определения.

Уравнение баланса элементного и минерального состава может быть представлено в следующем виде:

$$
\left[W_{i j}\right] \cdot\left[M_{j}\right]=\left[C_{i}\right]
$$

где $W_{i j}$ - матрица массовых долей $i$-х компонентов (оксидов элементов) в $j$-х минералах; $M_{j}-$ coдержания минералов в образце; $C_{i}$ - содержания компонентов в образце. Обратная задача определения содержания минералов по известному элементному составу в общем случае не может быть решена из-за неизвестного переменного состава ряда минералов, наличия изоморфных примесей элементов, а также когда число определяемых (идентифицированных) минералов превышает число элементов с известным содержанием.

Однако можно определить минимум (или максимум) содержания $M_{j}$ или суммы нескольких компонентов $\sum M_{j}$ (группы компонентов) при условии (1) или при условиях $\left|C_{j}-C_{j}^{\text {изм }}\right|<\varepsilon_{j}$, где $\varepsilon_{j}$ - погрешности определения содержаний элементов (обычно менее 0.1-0.5 мас. \% для основных породообразующих оксидов элементов). 
Минералы в табл. 2 были разбиты на условные группы: группа I - полевые шпаты (ортоклаз, альбит, анортит); группа II - слоистые и ленточные силикаты (клинохлор, мусковит, актинолит); группа III - оксиды (кварц и рутил). Клинохлор и актинолит были представлены в виде двух крайних членов - магниевого $\left(\mathrm{Mg}_{5} \mathrm{Al}\left(\mathrm{AlSi}_{3} \mathrm{O}_{10}\right)(\mathrm{OH})_{8}\right.$ и $\left.\mathrm{Ca}_{2} \mathrm{Mg}_{5} \mathrm{Si}_{8} \mathrm{O}_{22}(\mathrm{OH})_{2}\right)$ и железистого $\left(\mathrm{Fe}_{5} \mathrm{Al}\left(\mathrm{AlSi}_{3} \mathrm{O}_{10}\right)(\mathrm{OH})_{8}\right.$ и $\left.\mathrm{Ca}_{2} \mathrm{Fe}_{5} \mathrm{Si}_{8} \mathrm{O}_{22}(\mathrm{OH})_{2}\right)$ миналов. Таким образом, матрица составов $\left[W_{i j}\right]$ может быть представлена в виде 10 столбцов, соответствующих минеральным компонентам, и 8 строк, соответствующих оксидам породообразующих элементов. Элементы матрицы $W_{i j}$, являющие собой массовые доли оксидов, рассчитаны из стехиометрических формул миналов. Компонент $\mathrm{H}_{2} \mathrm{O}$ не включен в процедуры вычислений, поскольку молекулы воды часто содержатся в нестехиометрическом соотношении в минералах (например, в межслойном пространстве слоистых силикатов или в аморфном кремнеземе).

Для поиска экстремумов содержания минеральной группы использовали процедуру «поиск решения» (опции - поиск решения линейных задач симплекс-методом или поиск решения нелинейных задач), имеющуюся в надстройках программы MSExcel. Для рассматриваемых составов поиск экстремумов устойчиво сходится к решению вне зависимости от начального приближения содержания минеральных фаз.

На рис. 2 приведены диапазоны содержания фаз минеральных групп и фазы диоксида кремния, рассчитанные с помощью процедуры поиска экстремума и определенные методом рентгеновской дифрактометрии (XRD, X-ray diffraction) для проб оз. Хикушка, распределенных по глубине керна. В рассматриваемой идеализированной системе компонентов (миналов) содержание рутила определяется содержанием оксида титана. Для результатов рентгенофазового определения приведены интервалы погрешностей, соответствующие величине относительного стандартного отклонения $( \pm \mathrm{RSD})$. В целом вариации минерального состава, определенного методом рентгеновской дифрактометрии, и вариации содержаний основных породообразующих оксидов (табл. 1) относительно не велики и свидетельствуют о довольно стабильном режиме накопления минеральных осадков за период, соответствующий глубине керна.

Для минеральных фаз группы I (рис. $2 a$ ) и группы II (рис. 2б) результаты рентгенофазового определения (XRD) лежат в диапазоне между минимумом и максимумом их содержания, рассчитанного с помощью процедуры поиска экстремума исходя из элементного состава. Рассчитанный диапазон возможных содержаний минеральных фаз для групп I и II довольно широкий ( 20 мас. \%), приблизительно в два раза превышает интервал \pm RSD рентгенофазового анализа и превышает уровень относительного стандартного отклонения, соответствующего количественным определениям (30 \% отн.).

Использование дополнительных априори известных ограничений на содержание минералов (миналов) может уменьшить диапазон неопределенности. Например, дополнительное ограничение в процедуре поиска экстремума на содержание мусковита $M_{j}>10$ мас. \% приводит к двукратному уменьшению рассчитанного диапазона для группы II ( 10 мас. \%). Мы не использовали это ограничение, поскольку погрешность определения мусковита не была установлена. Включение в уравнение баланса вероятно присутствующего минерала вермикулита $\left(\mathrm{Mg}_{3.41}\left[\left(\mathrm{Si}_{3} \mathrm{Al}\right) \mathrm{O}_{10}\right] \cdot(\mathrm{OH})_{2} \cdot 4 \mathrm{H}_{2} \mathrm{O}\right)$ и условия, что его содержание менее 3 мас. \%, не приводит к изменению рассчитанных границ диапазона. 

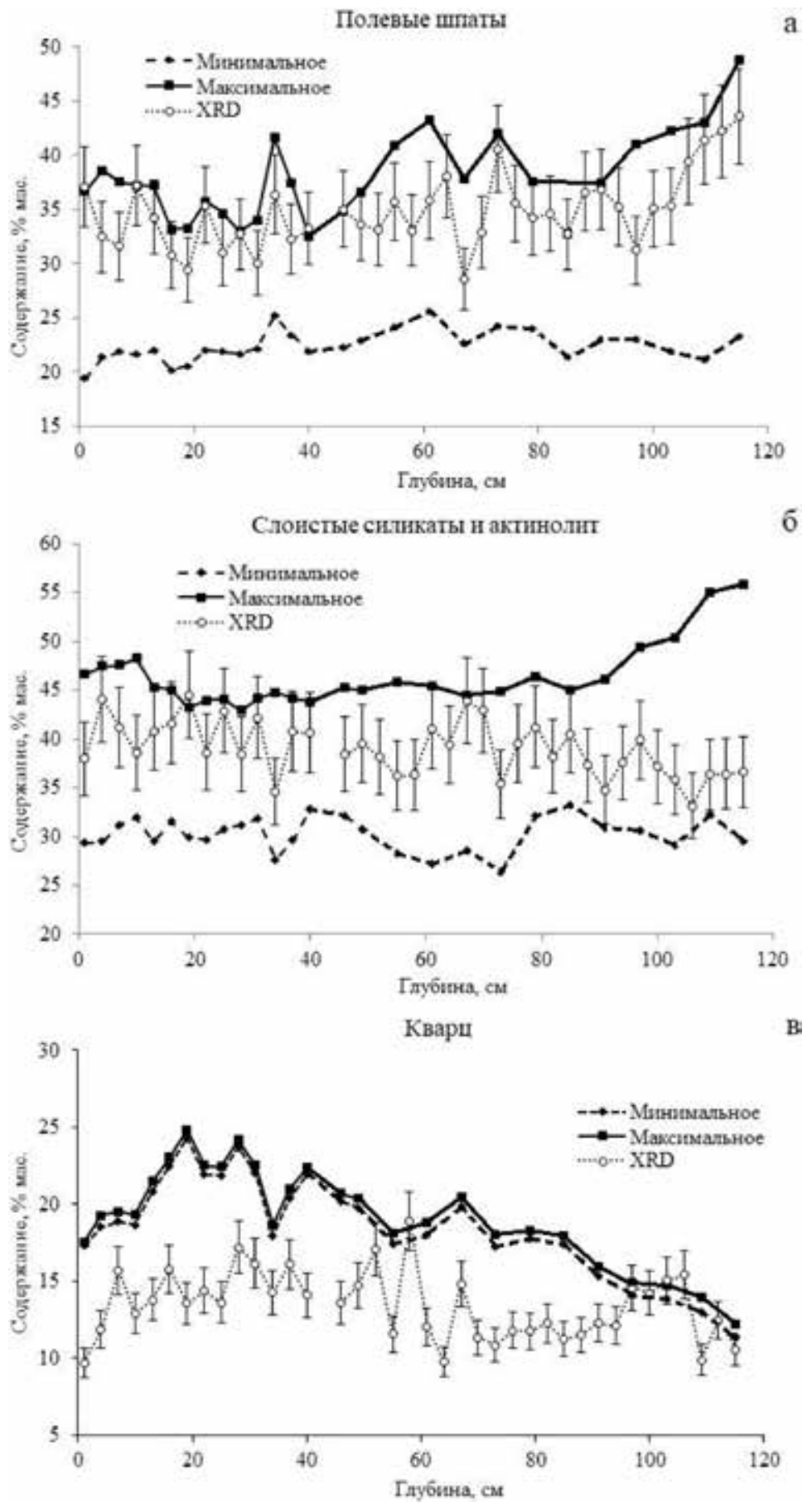

Рис. 2. Диапазоны содержания фаз минеральных групп и фазы диоксида кремния и результаты рентгеновской порошковой дифрактометрии (XRD)

Fig. 2. Ranges of the content of the phases of mineral groups and the silicon oxide phase and results of x-ray powder diffraction determination (XRD)

Обращает на себя внимание довольно узкий рассчитанный диапазон возможных содержаний фазы диоксида кремния $<1$ мас. \% (рис. 26). Результаты рентгенофазового опре- 
деления кварца $\left(M_{Q Z}^{X R D}\right)$ систематически занижены относительно рассчитанных содержаний фазы оксида кремния $\left(M_{S i O_{2}}^{X R F}\right)$. Разность средних по глубине керна значений $M_{Q Z}^{X R D}$ и $M_{S i O_{2}}^{X R F}$ составляет 7 мас. \% и больше погрешности определения. Это обстоятельство обусловлено присутствием аморфной фазы биогенного кремнезема $\left(\mathrm{SiO}_{2} \mathrm{bio}\right)$. На рис. 3 приведены дан-

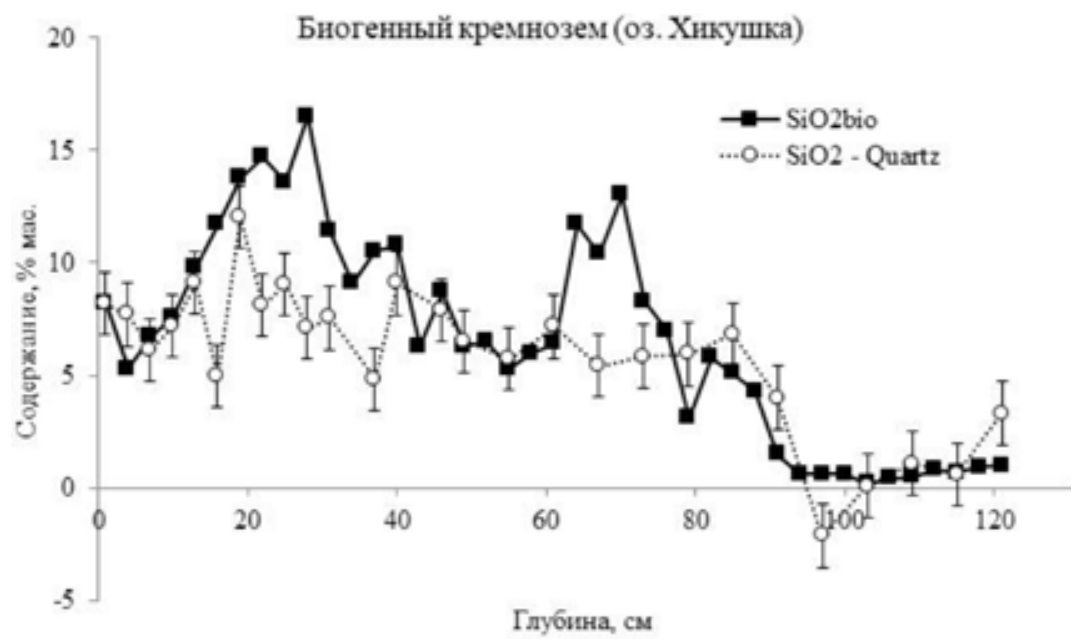

Рис. 3. Содержания $\mathrm{SiO}_{2}$ bio и разности между расчетным максимальным содержанием фазы оксида кремния и содержанием кварца $\left(\mathrm{SiO}_{2}-\right.$ Quarz)

Fig. 3. Contents of $\mathrm{SiO}_{2}$ bio and the differences between the calculated maximum contents of the silicon oxide phase and the quartz contents $\left(\mathrm{SiO}_{2}-\right.$ Quarz $)$

ные определения $\mathrm{SiO}_{2}$ bio и значения разности $\left(\mathrm{SiO}_{2}-\right.$ Quartz) между рассчитанными максимальными содержаниями фазы оксида кремния и содержаниями кварца, определенного методом рентгенофазового анализа. На рис. 3 видно общее согласие между поведением содержания $\mathrm{SiO}_{2}$ bio и разностью между рассчитанными содержаниями фазы оксида кремния и кварца по глубине керна.

На рис. 4 приведены результаты рентгенофазового определения содержания кварца (XRD) и расчетные минимальные и максимальные содержания фазы оксида кремния для образцов осадков оз. Ильчир, распределенных по глубине керна. Для большинства проб рассчитанный с помощью процедуры поиска экстремума диапазон возможных содержаний диоксида кремния перекрывается с интервалами погрешности определения кварца методом рентгеновской дифрактометрии. Расхождение средних по глубине содержаний диоксида кремния (18.8 мас. \%) и кварца (17.9 мас. \%) менее 1 мас. \% и незначимо на фоне погрешности определения. Приведенные данные (рис. 4) свидетельствуют о низком содержании аморфной фазы диоксида кремния (<2 мас. \%) в осадках оз. Ильчир. Содержание фазы диоксида кремния, определенное с помощью процедуры поиска экстремума с использованием данных об элементном составе, имеет меньшую величину неопределенности, чем при определении методом рентгенофазового анализа для рассматриваемого типа составов осадков оз. Ильчир. 


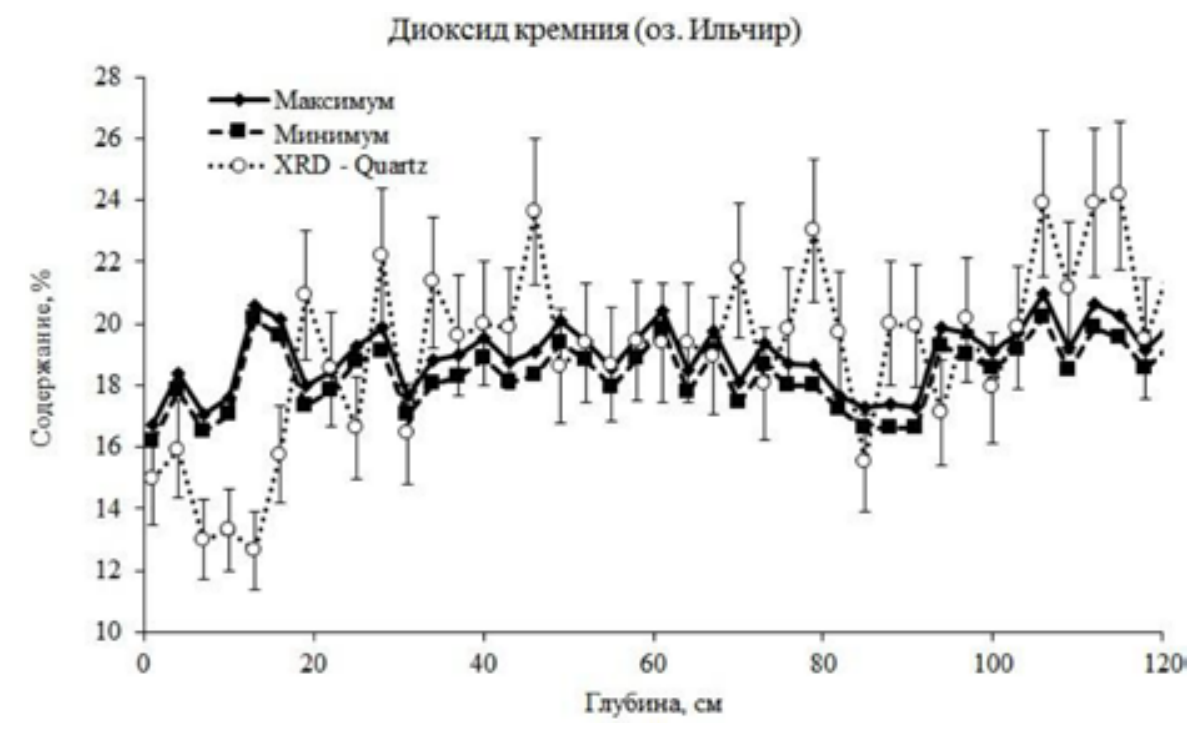

Рис. 4. Результаты рентгенофазового определения содержания кварца (XRD, Quartz) и расчетные минимальные и максимальные содержания фазы диоксида кремния

Fig. 4. Results of $\mathrm{x}$-ray powder diffraction determination of quartz content and calculated minimum and maximum contents of the silicon dioxide phase

\section{Выводы}

Рассматриваемый способ оценки диапазона содержания минеральных групп силикатных донных отложений озер, основанный на данных рентгенофлуоресцентного анализа об элементном составе и качественного рентгенофазового анализа, может быть полезен для оценки вариации минерального состава по глубине керна донных отложений в условиях часто имеющего место дефицита материала отдельных проб керна, распределяемого между различными методами анализа. Способ прост в реализации и использует общедоступное программное обеспечение MS Excel. Сравнение с данными количественного рентгенофазового анализа показывает, что, несмотря на идеализированную модель минерального состава, способ позволяет оценить возможный диапазон содержания некоторых минеральных групп с «нестехиометрическим» элементным составом. Систематическое расхождение между результатами расчета содержания фазы диоксида кремния и результатами количественного рентгенофазового определения кварца для рассматриваемых составов проб обусловлено присутствием рентгеноаморфной фазы биогенного кремнезема. Этот результат открывает возможность косвенного обнаружения аморфной фазы диоксида кремния.

\section{Благодарности / Acknowledgements}

Исследования выполнены с использованием оборудования Центра коллективного пользования «Изотопно-геохимических исследований» Института геохимии им. А.П. Виноградова СО РАН (ИГХ СО РАН). Рентгенофлуоресцентный и рентгенофазовый анализ выполнены при финансовой поддержке РФФИ (проект № 19-05-00328) и в соответствии с государственным заданием ИГХ СО РАН (проект № 0350-2017-0026). Авторы выражают благодарность сотрудникам ИГХ СО РАН: Е.В. Безруковой за полезное обсуждение работы и предоставленные 
данные о возрасте осадков, О.В. Левиной за определение содержаний биогенного кремнезема, А.А. Щетникову, И.А. Филинову, Е.В. Иванову, М.А. Крайнову, проводившим бурение и обработку образцов кернов.

The research was carried out using the equipment of the Center for collective use of "Isotopegeochemical research" of the A.P. Vinogradov Institute of Geochemistry SB RAS (IGC SB RAS). $\mathrm{X}$-ray fluorescence and X-ray phase analysis were performed with the financial support of the Russian Science Foundation (project no. 19-05-00328) and in accordance with the state task of the IGC SB RAS (project no. 0350-2017-0026). The authors express their gratitude to the staff of the IGC SB RAS: E.V. Bezrukova for a useful discussion of the work and provided data on the age of deposits, O.V. Levina for determining the content of biogenic silica, A.A. Schetnikov, I.A. Filinov, E.V. Ivanov, M.A. Krainov, who conducted drilling and processing of core samples.

\section{Список литературы / References}

1. Кузьмин М.И., Бычинский В.А., Кербер Е.В., Ощепкова А.В., Горегляд А.В., Иванов Е.В. Химический состав осадков глубоководных байкальских скважин как основа реконструкции изменений климата и окружающей среды. Геология и геофизика 2014. Т. 55(1), С. 3-22 [Kuz'min M.I., Bychinskij V.A., Kerber E.V., Oshhepkova A.V., Goregljad A.V., Ivanov E.V. Himicheskij sostav osadkov glubokovodnyh Bajkal'skih skvazhin kak osnova rekonstrukcii izmenenij klimata i okruzhajushhej sredy. The chemical composition of sediments of the Baikal deep-water wells as a basis for the reconstruction of climate change and the environment. Russian Geology and Geophysics 2014. Vol. 55(1) P. 3-22 (In Russ.)]

2. Скляров Е.В., Солотчина Э.П., Вологина Е.Г., Игнатова Н.В., Изох О.П., Кулагина Н.В., Склярова О.А., Солотчин П.А., Столповская В.Н., Ухова Н.Н., Федоровский В.С., Хлыстов О.М. Детальная летопись климата голоцена из карбонатного разреза соленого озера ЦаганТырм, Западное Прибайкалье. Геология и геофизика 2010. T. 51(3), С. 303-328. [Skljarov E.V., Solotchina Je.P., Vologina E.G., Ignatova N.V., Izoh O.P., Kulagina N.V., Skljarova O.A., Solotchin P.A., Stolpovskaja V.N., Uhova N.N., Fedorovskij V.S., Hlystov O.M. Detailed Holocene climate record from the carbonate section of saline lake Tsagan-Tyrm (West Baikal area). Russian Geology and Geophysics 2010. Vol. 51(3), P. 303-328 (In Russ.)]

3. Безрукова Е.В., Щетников А.А., Кузьмин М.И., Шарова О.Г., Кулагина Н.В., Летунова П.П., Иванов Е.В., Крайнов М.А., Кербер Е.В., Филинов И.А., Левина О.В. Первые данные об изменении природной среды и климата Жомболокского вулканического района (Восточный Саян) в среднем-позднем голоцене. Доклады Академии наук 2016. Т. 468(3), С. 323-327. [Bezrukova E.V., Shhetnikov A.A., Kuz'min M.I., Sharova O.G., Kulagina N.V., Letunova P.P., Ivanov E.V., Krajnov M.A., Kerber E.V., Filinov I.A., Levina O.V. First data on changes in the natural environment and climate of the Zhombolok volcanic region (East Sayan) in the middle-late Holocene. Doklady Earth Sciences 2016. Vol. 468(3), P. 323-327. DOI: 10.7868/S0869565216150172 (In Russ.)]

4. Безрукова Е.В., Амосова А.А., Чубаров В.М., Финкельштейн А.Л., Кулагина Н.В. Изменение природной среды северо-востока Республики Бурятия в пост-оптимальный период голоцена: первые результаты. Сибирский экологический журнал 2017. Т. 24(4), С. 498-511. [Bezrukova E.V., Amosova A.A., Chubarov V.M., Finkelshtein A.L., Kulagina N.V. Changes in the natural environment of the North-East of the Republic of Buryatia in the post-optimal Holocene period: 
first results. Sibirskii ekologicheskii zhurnal 2017. Vol. 24(4), P. 498-511. DOI: 10.15372/SEJ20170410 (In Russ.)]

5. Rydberg J. Wavelength dispersive X-ray fluorescence spectroscopy as a fast, non-destructive and cost-effective analytical method for determining the geochemical composition of small loosepowder sediment samples. Journal of Paleolimnology 2014, Vol. 52, P. 265-276

6. Davies S., Lamb H., Roberts S. Micro-XRF Core Scanning in Palaeolimnology: Recent Developments. Croudace I., Rothwell R. (eds) Micro-XRF Studies of Sediment Cores. Developments in Paleoenvironmental Research 2015. Vol. 17, P. 189-226.

7. Амосова А.А., Чубаров В.М., Канева Е.В., Маркова Ю.Н. Определение основных породообразующих элементов, стронция и циркония рентгенофлуоресцентным методом для геохимической характеристики донных отложений. Аналитика и контроль 2017. Т. 21(1), С. 16-24. [Amosova A.A., Chubarov V.M., Kaneva E.V., Markova Yu.N. Determination of main rock-forming elements, strontium and zirconium by X-ray fluorescence analysis for the geochemical characterization of bottom. Analytics and Control 2017. Vol. 21(1), P. 16-24, DOI: 10.15826/analitika.2017.21.1.003 (In Russ.)]

8. Amosova A.A., Chubarov V.M., Pashkova G.V., Finkelshtein A.L., Bezrukova E.V. Wavelength dispersive X-ray fluorescence determination of major oxides in bottom and peat sediments for paleoclimatic studies. Applied Radiation and Isotopes 2019. Vol. 144, P. 118-123.

9. Opitz S., Wünnemann B., Aichner B., Dietze E., Hartmann K., Herzschuh U., IJmker J., Lehmkuhl F., Li S., Mischke S., Plotzki A., Stauch G., Diekmann B. Late Glacial and Holocene development of Lake Donggi Cona, north-eastern Tibetan Plateau, inferred from sedimentological analysis. Palaeogeography, Palaeoclimatology, Palaeoecology 2012. Vol. 337, P. 159-176.

10. Hupp B.N., Donovan J.J. Quantitative mineralogy for facies definition in the Marcellus Shale (Appalachian Basin, USA) using XRD-XRF integration. SedimentaryGeology 2018. Vol. 371, P. 16-31.

11. Смелый Р.В., Канева Е.В., Ощепкова А.В., Бычинский В.А., Айсуева Т.С., Щетников А.А., Пашкова Г.В., Якимов И.С., Финкельштейн А.Л. Определение минерального состава озерных донных отложений методами рентгеновской дифракции и физико-химического моделирования. Журнал Сибирского федерального университета. Химия 2019. Т. 12(3). С. 382394. [Smelyy R.V., Kaneva E.V., Oshchepkova A.V., Bychinskii V.A., Aisueva T.S., Shchetnikov A.A., Pashkova G.V, Yakimov I.S., Finkelshtein A.L. Determination of the mineral composition of the lake bottom sediments by X-ray diffraction method and physico-chemical modelling, J. Sib. Fed. Univ. Chem. 2019, Vol. 12(3), P. 382-394. DOI: 10.17516/1998-2836-0135 (In Russ.)]

12. Солотчина Э.П. Структурный типоморфизм глинистых минералов осадочных разрезов и кор. Новосибирск: Гео, 2009. 234 с. [Solotchina Je.P. Structural typomorphism of clay minerals of sedimentary sections and crusts. Novosibirsk, Geo Publ., 2009. 234 p. (In Russ.)]

13. Жданова А.Н., Солотчина Э.П., Солотчин П.А., Кривоногов С.К., Даниленко И.В. Отражение изменений климата голоцена в минералогии донных осадков ярковского плеса озера Чаны (юг Западной Сибири). Геология и геофизика 2017. T. 58(6), С. 856-868. [Zhdanova A.N., Solotchina E.P., Solotchin P.A., Krivonogov S.K., Danilenko I.V. Reflection of Holocene climatic changes in mineralogy of bottom sediments from Yarkovsky Pool of Lake Chany (southern West Siberia). Russian Geology and Geophysics 2017. Vol. 58(6), P. 692-701. In Russ.)]

$$
-271-
$$


14. Ощепкова А.В., Кузьмин М.И., Бычинский В.А., Солотчина Э.П., Чудненко К.В. Модели твердых растворов для расчета минерального состава донных осадков озера Байкал: новый подход к палеоклиматическим реконструкциям. Доклады Академии наук 2015. Т. 461(4), C. 47-450. [Oshhepkova A.V., Kuz'min M.I., Bychinskij V.A., Solotchina Je.P., Chudnenko K.V. Solid solution models for the calculation of the mineral composition of lake Baikal bottom sediments: a new approach to paleoclimatic reconstructions. Doklady Earth Sciences 2015. Vol. 461(4), P. 447-450. DOI: $10.7868 / \mathrm{S} 0869565215100229$ (In Russ.)]

15. Скляров Е.В., Солотчина Э.П., Вологина Е.Г., Изох О.П., Кулагина Н.В., Орлова Л.А., Склярова О.А., Солотчин П.А., Столповская В.Н., Ухова Н.Н. Климатическая история голоцена Западного Прибайкалья в карбонатной осадочной летописи озера Холбо-Нур. Доклады Академии наук 2010. T. 431(5), C. 668-674. [Skljarov E.V., Solotchina Je.P., Vologina E.G., Izoh O.P., Kulagina N.V., Orlova L.A., Skljarova O.A., Solotchin P.A., Stolpovskaja V.N., Uhova N.N. The climatic history of the Holocene of the Western Baikal region in carbonate sedimentary chronicle of lake Holbo-Nur. Doklady Earth Sciences 2010. Vol. 431(5), P. 668-674 (In Russ.)]

16. Raven M.D., Self P.G. Outcomes of 12 Years of the Reynolds Cup Quantitative Mineral Analysis Round Robin. Clays Clay Miner 2017. Vol. 65(2), P. 122-134.

17. DIFFRAC Plus Evaluation package EVA. User's Manual, Bruker AXS, Karlsruhe, Germany, 2007.

18. Topas V4: General profile and structure analysis software for powder diffraction data. User's Manual, Bruker AXS, Karlsruhe, Germany, 2008.

19. ICDDProducts. [Электронный pecypc]: http://www.icdd.com/products/ (дата обращения 15.02.2019).

20. Якимов И.С., Дубинин П.С., Залога А.Н., Пиксина О.Е., Якимов Я.И. Регуляризация методов бесстандартного рентгенофазового анализа. Журн. структурной химии 2011. Т. 52(2), C. 329-335. [Yakimov I.S., Dubinin P.S., Zaloga A.N., Piksina O.E., Yakimov Ya.I. Regularization of methods of a standardless X-ray phase analysis. Journal of Structural Chemistry 2011. Vol. 52(2), P. 319-325 (in Russ.)] 